\title{
STATE OF RESIDUAL STRESSES AFTER THE PROCESS OF MILLING SELECTED ALUMINIUM ALLOYS
}

\author{
Józef Kuczmaszewski ${ }^{1}$, Waldemar Łogin², Paweł Pieśko', Ireneusz Zagórski \\ 1 Department of Production Engineering, Faculty of Mechanical Engineering, Lublin University of Technology, \\ Nadbystrzycka 36, 20-618 Lublin, Poland, e-mail: j.kuczmaszewski@pollub.pl, p.piesko@pollub.pl, \\ i.zagorski@pollub.pl \\ 2 PZL Mielec a Sikorsky Company, Wojska Polskiego 3, 39-300 Mielec, Poland, e-mail:waldemar.login@Imco.com
}

Received: 2017.10.23

Accepted: 2018.02.01

Published: 2018.03.01

\begin{abstract}
The purpose of this paper was to analyse the structure and the state of residual stresses in the samples made of rolled AW-2024 and AW-7075 aluminium alloy plates, prior to machine cutting and after the process of milling under various machining conditions. The state of stresses was evaluated on the basis of measurements by means of $\sin 2 \mathrm{vF} X$-ray diffractometry and layer removal method. Furthermore, top layer microstructures were compared in half-finished product, machined product, and core material samples.
\end{abstract}

Keywords: aluminium alloys, high speed machining, residual stresses.

\section{INTRODUCTION: STATE OF KNOWLEDGE}

The attempts to reduce aircraft mass and to maintain concurrently its operating characteristics (increased performance, range, load-carrying capacity, durability, and reliability; decreased fuel consumption) result largely from economic aspects and make the designers and manufacturers use new materials as well as new design solutions, which means the adoption of new production and assembling technologies. The need to simplify the assembling procedures by way of reduction in the number of elements to be connected by means of various methods, such as e.g. riveting, bonding, or welding, or else of complete elimination of joints thanks to monolithic elements, was the reason of construction and application of structural (integral) structures in aircraft industry. Moreover, reduction in, or complete elimination of joints may limit the scope of in-service maintenance and inspection procedures. Shown in fig. 1 are the examples of integral structures used to design the Future Lynx AW159 Augusta Westland helicopter.
Compared with multiple-element structures, the structures of this kind offer a number of benefits, such as:

- Increased resistance and rigidity;

- Decreased mass;

- Shortened and simplified assembling works,

- Increased precision and durability of the structure.

Apart from plate or frame type structures (fig. 1), the industry uses also closed-plate structures where the connecting ribs and the outside coating are homogenous elements. Examples of such structures are the elements produced by means of Goodrich proprietary GRID-LOCK ${ }^{\circledR}$ technology (fig. 2).

The said technology is used to manufacture lightweight structural elements which may transfer considerable loads and prove more durable and resistant to damages and corrosion when compared with their equivalents containing honeycomb structure filling. Among other things, such structures are used to manufacture [7]:

- Bulkheads in AV- 8B Harrier;

- Rigid cargo barriers in Boeing 727; 


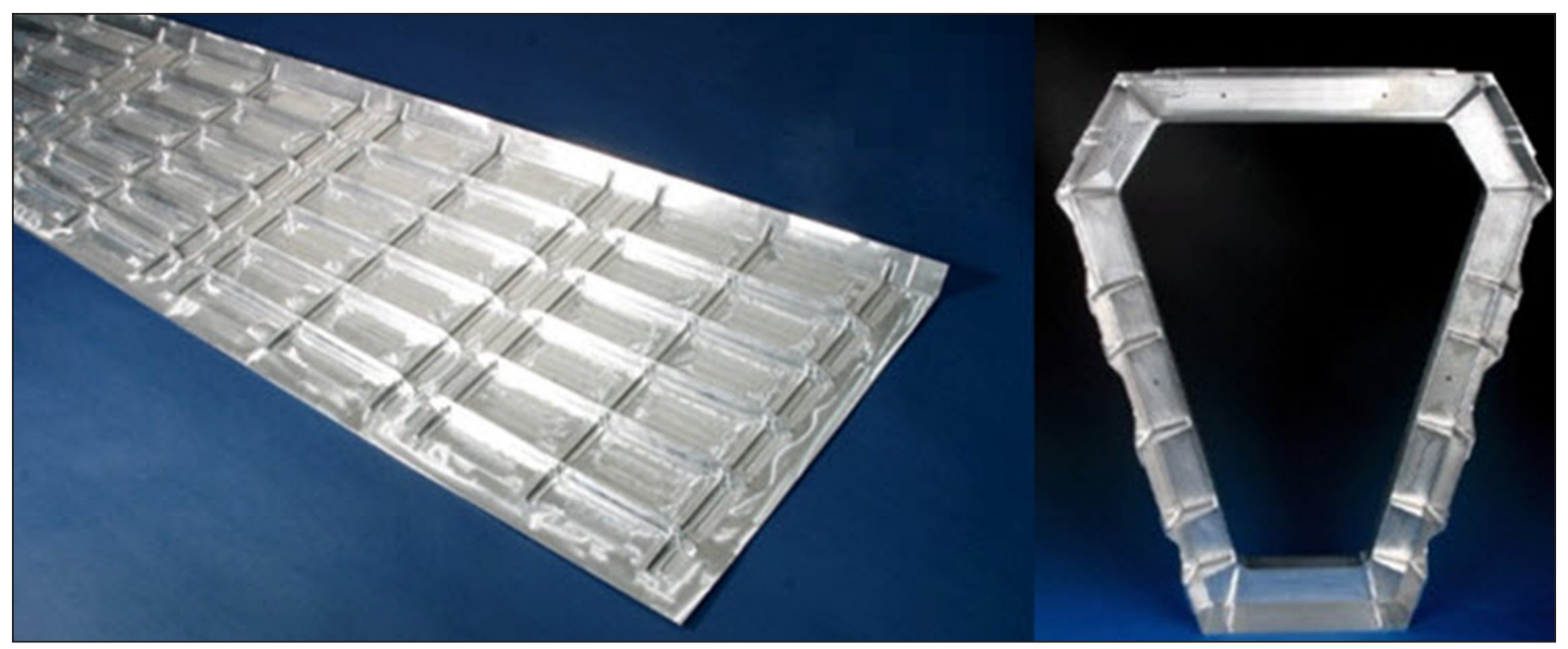

Fig. 1. Examples of integral elements used in helicopter design [8]



Fig. 2. Aircraft control surface element made by means of GRID-LOCK ${ }^{\circledR}$ technology [7]

- Roof structures in ICT satellites;

- Nose, landing gear doors, and elements of control surfaces in F - 16 fighter aircraft, and

- C -5 transport aircraft poles and elements of nacelle system, and other components.

Research into the said field should lead to the development of designs and technologies of manufacturing closed-plate elements which will have the widest possible area of use (e.g.: elements of sheathing, wing design, control surfaces, etc.) and whose base-to-cover joint will rely on mechanical elements only with no need of bonding. The results should simplify and shorten the assembling works as well as maintain, or even upgrade, resistance parameters of such structures at the same time. The elements of the kind (figs. 1 and 2) are mostly manufactured from rolled $\mathrm{Al}$ alloy plates, almost all by means of machining methods. In order to manufacture a thin-wall structure of a large surface and often considerable wall height compared with its thickness and to maintain simultaneously a high performance requires the use of specific machining methods, such as High Speed Machining and High Productive Cutting. The said methods are likely to strengthen the development of considerable post-machining stresses and changes in the top layer. Residual stresses occur also in the half-finished product itself because of the history of its production. Hence, the entire process of production of an element has an impact on the state of residual stresses and on the microstructure of the top layer. A finished product is manufactured by means of damage-free processes (casting; plastic forming, etc.) which usually precede the machining and thermal treatment operations. All such processes have an impact on the structure and residual stresses in the finished product, specifically on the condition of its surface layer.

For the period of machining, the workpiece is exposed to high stresses and unit pressures in the zone of chip formation as well as to highgradient high-temperature field. These phenomena produce durable changes in the surface layer, 
which may be described by way of comparative studies into:

- Microstructure;

- Micro-hardness, and

- State of residual stresses.

The structure of surface layer (fig. 3) after machining is of sector type with perceptible zones of impact of elastic and plastic strains as well as a zone of impact of thermal effects. Shown in fig. 4 is the draft representation of the impact of various agents on the condition and structure of surface layer.

Shown below are certain variables which control the values of generated cutting forces [3]:

- Cutting parameters: $\mathrm{v}_{\mathrm{c}}, \mathrm{a}_{\mathrm{p}}, \mathrm{f}$;

- Tool cutting blade characteristics: blade material, geometry, and wear;

- Machined material features, and

- Machining fluid: type and method of supply.

Inside the material, cutting forces combined with heat will generate the stress field and temperatures which may produce phase transitions due to change in volumes of individual phases and to development of additional stresses. Stresses produced by cutting forces, temperature variability, and phase transitions will overlap and generate elastic and plastic strains which bring about internal work-hardening, structure orientation, and changes in mechanical characteristics of surface layer, such as e.g. micro-hardness and residual stresses [3].
The reasons of formation of residual stresses may be described by means of the models mentioned below [3]:

- Mechanical model (fig. $5 \mathrm{a}, \mathrm{b}$ );

- Thermal model (fig. $5 \mathrm{c}, \mathrm{d}$ ), and

- Structural-volumetric model: phase transitions occur under the impact of stresses and temperature. Stresses are generated due to the fact that individual phases feature various specific volumes.

Practically, all the agents, i.e. mechanical, thermal, and structural agents have an impact on the state of stresses. Their intensity, however, may be different. Mechanical model is typical of chip machining with tools of defined blade geometry. Thermal model corresponds to the abrasive machining; it may, however, prevail also in chip machining at very high cutting speeds (e.g. in HSM). Post-cutting residual stress occurrence depth amounts to ca. $0.1 \div 0.25 \mathrm{~mm}$ according to fig. 6 and reference data $[2,9,11]$.

A number of research methods (fig. 6) [1, 10] have been developed for the purpose of determination of residual stresses:

- Non-destructive (e.g. X-ray diffraction; ultrasonic; eddy current, etc.);

- Destructive (e.g. ring-core, layer removal method, etc.).

The present study used the X-ray diffraction methods.

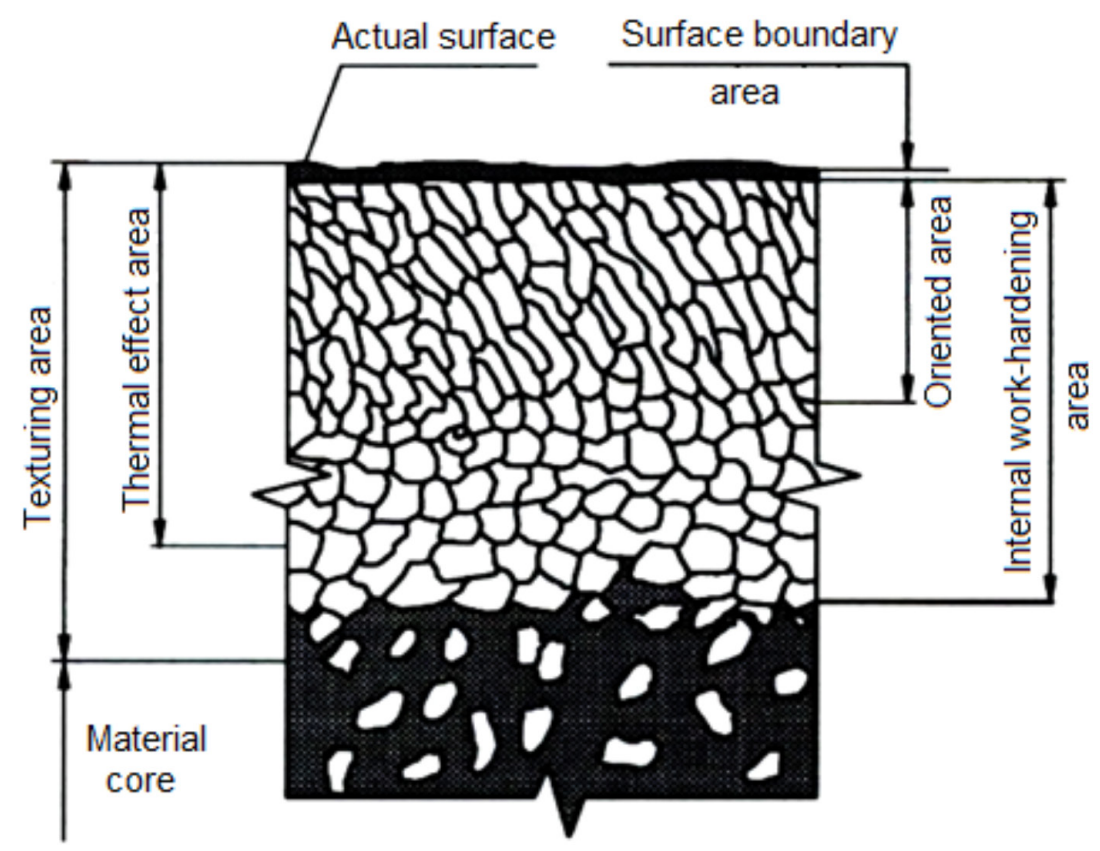

Fig. 3. Surface layer structure [5] 


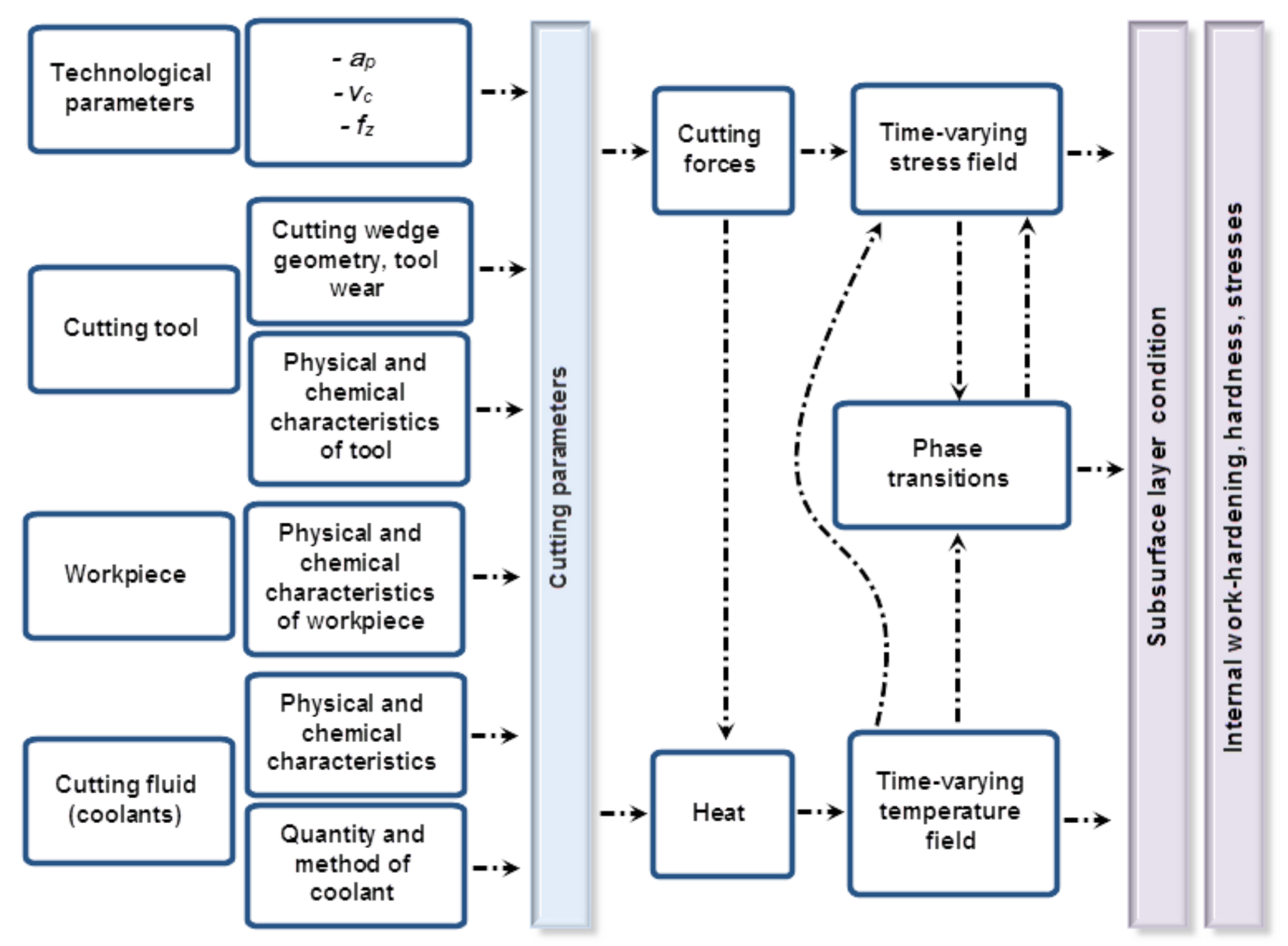

Fig. 4. Agents controlling the condition of surface layer [3]

\section{METHODOLOGY AND AIM OF STUDY}

Two AW-2024 T351 and AW-7075 T651 aluminium alloys were used as sample materials in the study. Such alloys are defined as "air-grade aluminium alloys" and feature elevated resistance parameters at good machining ability. Chemical composition of selected aluminium alloys are shown in Table 1 (data according to bibliographic references).

Prior to the assessment, fundamental mechanical characteristics of the said alloys were determined on the basis of static tensile test; results are shown in Table 2.

\section{X-RAY DIFFRACTION METHOD}

The X-ray diffraction method was used to study the state of stresses in half-finished product (fig. 8) and in samples after machine cutting (fig. $7 \mathrm{a}, \mathrm{b})$. Four samples were prepared and worked under different technical conditions (Table 3). Samples 1 and 3 were machined at the same cut- ting speed $\mathrm{v}_{\mathrm{c}}=400 \mathrm{~m} / \mathrm{min}$, yet at different rates of feed and of cutting depth; on the other hand, samples 2 and 4 were machined at higher cutting speed $\mathrm{v}_{\mathrm{c}}=900 \mathrm{~m} / \mathrm{min}$, which corresponded to HSM process. Reference material marked as "zero" sample was cut from a rolled plate (fig. 8).

$\mathrm{X}$-ray diffraction testing was carried out on the apparatus for measurement of residual stresses and of retained austenite content from PROTO Manufacturing Ltd.Windsor, Ontario, Canada (fig. 7c) acc. to the Testing Procedure LMiAC IMN PB-N.

The characteristics were measured immediately on machined surfaces and after spot electrochemical polishing with removal of layers every $0.1 \mathrm{~mm}$ down to the depth of $0.3 \mathrm{~mm}$ (fig. $7 \mathrm{~b})$. Stress values were measured in the parallel direction $\mathrm{KW}$ and perpendicular direction $\mathrm{KP}$ with regard to the direction of half-finished product rolling (fig. 8).

Shown in fig. 8 are locations of areas on Surfaces KW and KP where metallographic microsections were made together with measurements of residual stresses. 



Fig. 5. Models of residual stress formation in surface layer: (a), (b) mechanical model; (c), (d) thermal model (figs. a, c: stresses in cutting zone; fig. b, d: post-machining stresses) [3]



Fig. 6. Post-cutting residual stress occurrence depth in surface layer with applicable measuring methods [1] 
Table 1. Chemical composition of selected Al alloys [6]

\begin{tabular}{|c|c|c|c|c|c|c|c|c|c|c|c|c|}
\hline Symbol & Symbol & \multicolumn{2}{|c|}{ Symbol } & Grade & \multicolumn{5}{|c|}{ Levels of elements [\%] } \\
\hline Acc. to PN-EN 573-3 & $\begin{array}{c}\text { Acc. to } \\
\text { ASTM }\end{array}$ & \multicolumn{2}{|c|}{ Acc. to PN-76/88026 } & Si & Fe & Mg & $\mathrm{Cu}$ & $\mathrm{Mn}$ & $\mathrm{Zn}$ & $\mathrm{Cr}$ & $\mathrm{Zr}+\mathrm{Ti}$ & Other \\
\hline EN AW-AICu4Mg1 & 2024 & AlCu4Mg1 & PA7 & $\leq 0.5$ & $\leq 0.5$ & 1.5 & 4.2 & 0.6 & $\leq 0.25$ & $\leq 0.1$ & $\leq 0.2$ & $\leq 0.15$ \\
\hline EN AW-AlZn5,5MgCu & 7075 & AlZn6Mg2Cu & PA9 & $\leq 0.4$ & $\leq 0.5$ & 2.5 & 1.6 & $\leq 0.3$ & 5.6 & 0.23 & $\leq 0.2$ & $\leq 0.25$ \\
\hline
\end{tabular}

Table 2. Fundamental mechanical characteristics of selected Al alloys [4]

\begin{tabular}{|c|c|c|c|c|c|c|}
\hline \multirow{2}{*}{ Material } & $\mathrm{E}$ & $\mathrm{Rp}_{0,1}$ & $\mathrm{Rt}_{0,5}$ & $\mathrm{Rm}$ & $\mathrm{Ag}$ & $\mathrm{A}_{5,65}$ \\
\cline { 2 - 7 } & {$[\mathrm{GPa}]$} & {$[\mathrm{MPa}]$} & {$[\mathrm{MPa}]$} & {$[\mathrm{MPa}]$} & $\%$ & $\%$ \\
\hline $\mathrm{AW}-7075$ & 72 & 453 & 347 & 564 & 8.35 & 10.2 \\
\hline $\mathrm{AW}-2024$ & 78 & 347 & 342 & 423 & 2 & 4 \\
\hline
\end{tabular}

Table 3. Summary of cutting parameters of samples for diffractometric tests

\begin{tabular}{|c|c|c|c|c|}
\hline Sample no. & $\mathrm{a}_{\mathrm{p}}[\mathrm{mm}]$ & $\mathrm{v}_{\mathrm{c}}[\mathrm{m} / \mathrm{min}]$ & $\mathrm{f}_{\mathrm{z}}[\mathrm{mm} / \mathrm{min}]$ & $a_{\mathrm{e}}[\mathrm{mm}]$ \\
\hline 0 & \multicolumn{4}{|c|}{ Post-rolling sample (no treatment) } \\
\hline 1 & \multirow{4}{*}{0,5} & 400 & 0.05 & 4 \\
\hline 2 & & 900 & 0.05 & 4 \\
\hline 3 & & 400 & 0.2 & 8 \\
\hline 4 & & 900 & 0.2 & 8 \\
\hline
\end{tabular}

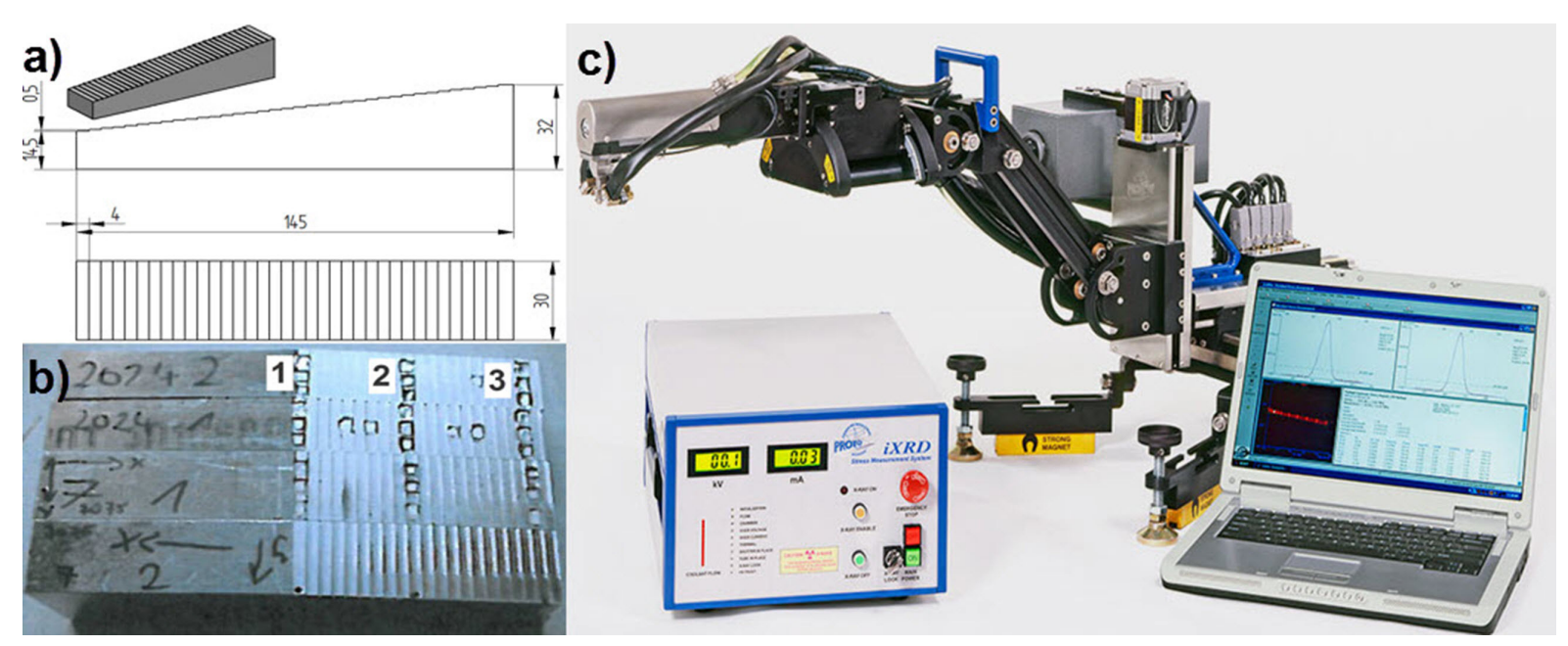

Fig. 7. Diffractometric tests: a) model of the sample; b) view of the sample; c) test bench [4]

\section{MICROSTRUCTURE TESTING}

Structure was tested by means of optical microscopy on the Olympus microscope GX-71 acc. to the Testing Procedure LMiAC IMN PB0 . Samples (metallographic microsections) were machined by means of mechanical polishing. Grain was developed by means of anodic oxidation in Barker reagent and viewed in polarised light. Lay-out and symbols identifying the places of individual metallographic microsections and pictures are shown in fig. 8 .
For AW-2024 alloy, metallographic microsection pictures were identified as $2 \mathrm{xxx}+$ sample number and as $7 \mathrm{xxx}+$ sample number for $\mathrm{AW}$ 7075 alloy. Metallographic microsections and pictures were taken from "raw" Surface PR of rolled plate (metallographic microsection identifiers: $7 \mathrm{xxx}$ surface, $2 \mathrm{xxx}$ surface) as well as from Surface PP perpendicular to "raw" Surface PR (metallographic microsection identifiers: 7xxx P, 7xxx S, 7xxx F, 2xxx 1, 2xxx 2, 2xxx 3). Furthermore, metallographic images were taken from the inside of the sample on the plane parallel to Sur- 


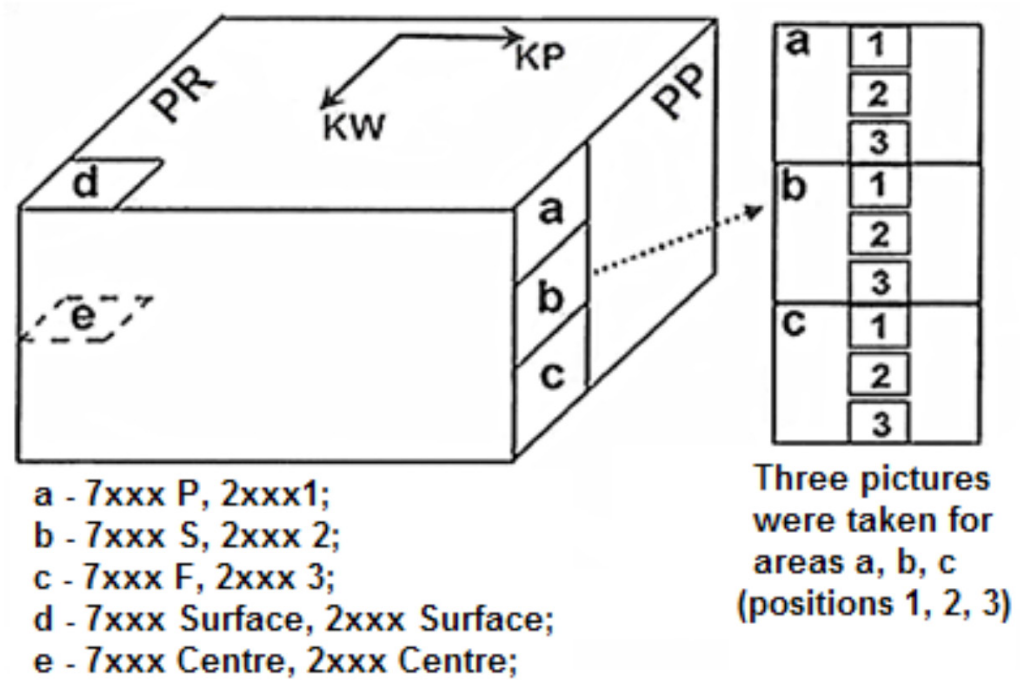

Fig. 8. Lay-out and symbols of areas designed for metallographic analysis and residual stress measurements on samples cut out from AW-2024 and AW-7075 alloy rolled plates

face PR (metallographic microsection identifiers: $7 \mathrm{xxx}$ centre, $2 \mathrm{xxx}$ centre).

\section{TEST RESULTS AND ANALYSIS}

\section{Microstructure testing}

In the case of AW-2024 alloy, developments of inter-metallic phases found at the surface (area „a" on Surface PP, fig. 8) were distributed uniformly - see fig. 9a. Within the core of the sample (area „b" on Surface PP - see fig. 8) released phases were distributed in strips on the grain boundaries (fig. 9b).

On planes parallel to Surface PR (areas „d" and ,e”, fig. 8), numbers of developments are visibly differentiated. They are much more frequent (fig. 10a) on Surface PR of the sample (area „d”, fig. 8) than within the core of the sample (area „e", fig. 8) where they appear on the grain boundaries (fig. 10b).

Furthermore, a considerable difference in grain sizes may be noticed on the surface and in the core of the sample. Grains within the core are much larger (figs. 9b and 10b) on the Plane PP and on the cross sections parallel to the rolling Plane PR (areas ,d" and ,e", fig. 8).

In the case of AW-7075 alloy, the structure of developed phases in all analysed areas is similar (figs. 11 and 12). The phases are uniformly distributed on the entire area of metallographic microsections and their number is unimportant.
In the case of metallographic microsections taken from Surface PP, sizes and shapes of grains at the surface of the sample (area „a", fig. 8) as well as within its core (area „b”, fig. 8) are similar, as evidenced in fig. 11. Grains are strongly extended in the direction of rolling. On the crosssection parallel to the rolling Plane PR (areas ,d" and ,e", fig. 8), the grains within the core of the sample (fig. 12b) are many times larger than the grains on the surface of the sample (fig. 12a).

The above mentioned structure of AW 2024 and AW 7075 alloy samples is typical of the rolled plates made of such alloys. Grains on Surface PP which is perpendicular to the rolling plane are extended in the rolling direction and their sizes are considerably larger within the core of the sample. A specifically large grain was found in AW 2024 alloy at the centre of the plate thickness.

\section{Measurement of residual stresses by means of X-ray diffractometry}

Shown in fig. 13 are the values of residual stresses in rolled samples (with no machining) as measured on Surface PR in rolling Direction KW and in Direction KP perpendicular to KW. Stresses were measured on a "raw" surface of the rolled plate (with no machining) and after removal of a $0.1 \mathrm{~mm}$ thick layer by means of etching.

In the case of AW-7075 alloy, residual stresses are positive on the surface of the sample and after removal of $0.1 \mathrm{~mm}$ layer by means of etching, whereas their values are higher in rolling Direc- 




Fig. 9. Microstructure of AW-2024 alloy: (a) at surface of the sample (area ,a”" on Surface PP, fig. 8), (b) within the core of the sample (area „,b” on Surface PP, acc. to fig. 8)

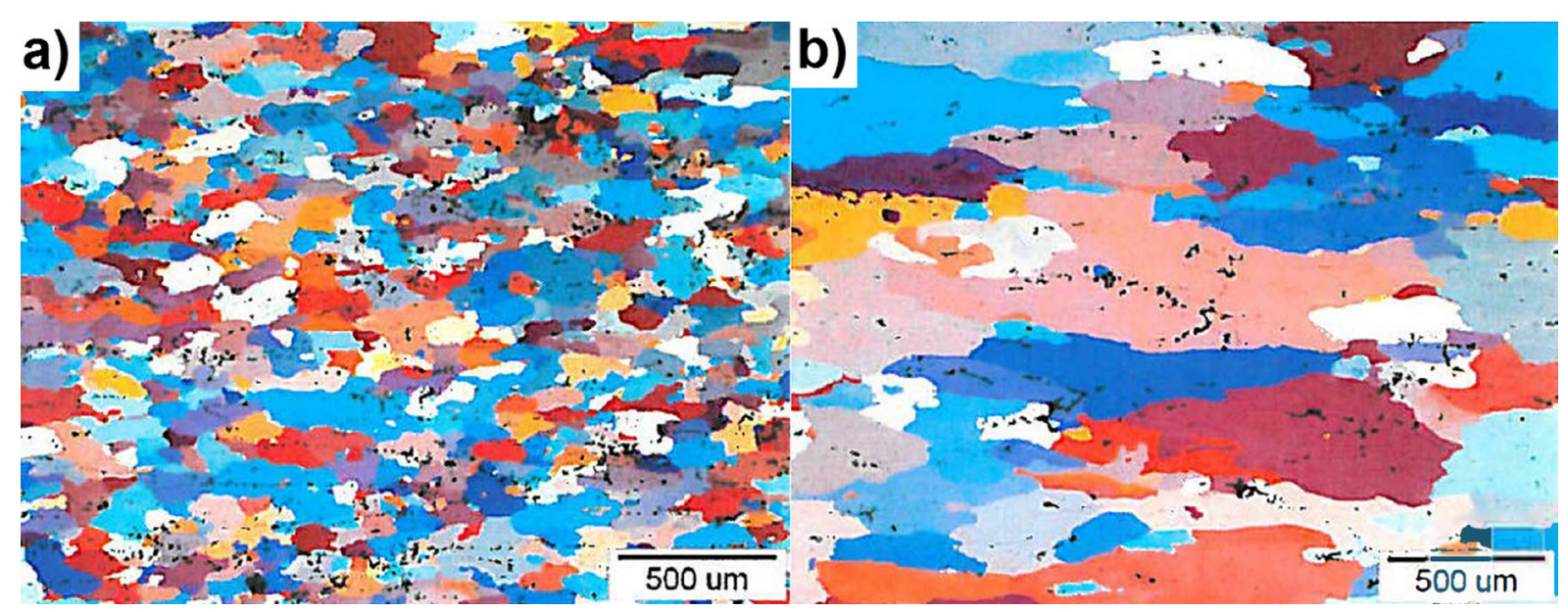

Fig. 10. Microstructure of AW-2024 alloy: (a) at surface of the sample (area „d” on Surface PR, fig. 8); (b) within the core of the sample (area „e" on the surface parallel to PR Surface, acc. to fig. 8)

a)

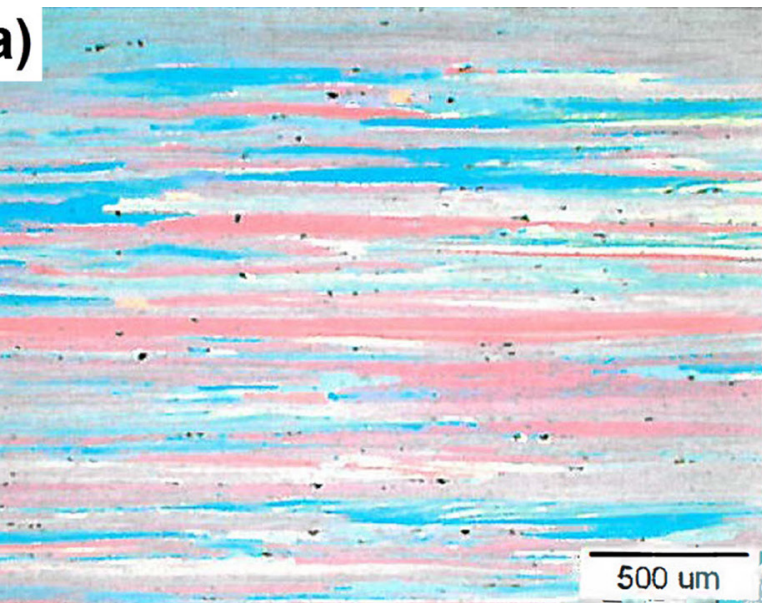

b)

Fig. 11. Microstructure of AW-7075 alloy: (a) at surface of the sample (area „a” on Surface PP, fig. 8); (b) within the core of the sample (area „b” on Surface PP, acc. to fig. 8) 


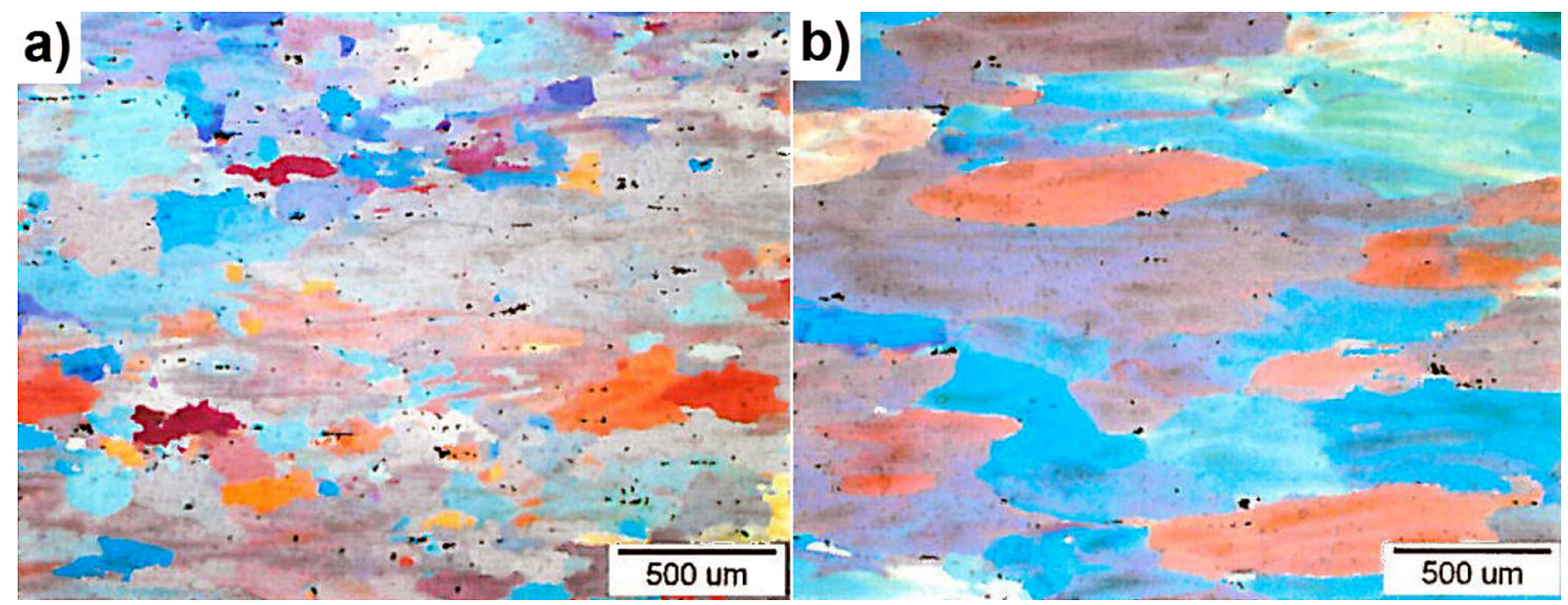

Fig. 12. Microstructure of AW-7075 alloy: (a) at surface of the sample (area „d” on Surface PR, fig. 8); (b) within the core of the sample (area ,e” on surface parallel to PR, acc. to fig. 8)

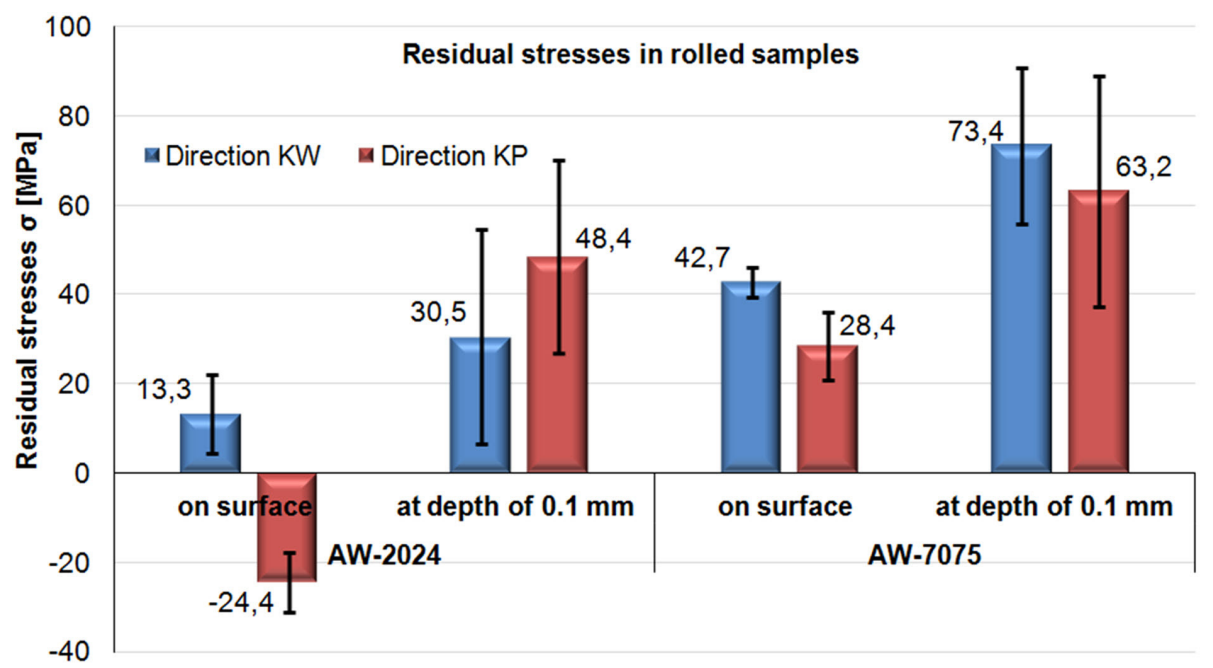

Fig. 13. Residual stresses in rolled samples (with no machining)

tion $\mathrm{KW}$, i.e. in the direction of grain extension. For the two alloys, the said stresses are stronger at the depth of $0.1 \mathrm{~mm}$ than on the surface of the samples. In the case of AW-2024 alloy, residual stresses on the surface of the sample are positive (tensile) in rolling Direction KW and negative (compressive) in Direction KP which is perpendicular to KW. After removal of $0.1 \mathrm{~mm}$ layer the stresses in the two directions proved tensile.

Shown in figs. 14 and 15 are the results of measurement of residual stresses in AW-2024 and AW-7075 alloys, respectively. The diagrams contain the values of residual stresses in four samples machined under various conditions (Table 3 ) as well as reference data on samples with no machining. Values of residual stresses for machined samples were measured on the surface identified by number 1 in fig. $7 \mathrm{~b}$.
In the case of AW-2024 alloy (fig. 14) we may state that in all the cases residual stresses in rolling Direction KW exceed the stresses in Direction $\mathrm{KP}$ which is perpendicular to KW. For smaller cross-sections of machined layer (samples 1 and 2) stresses are negative (compressive) whereas for larger cross-sections (samples 3 and 4) stresses are positive. With the same cross-sections of machined layer, increase in the cutting speed will increase the value of residual stresses.

In the two alloys submitted to small machining parameters (sample 1) the values of residual stresses in the two directions (KW and KP) are smaller (negative, i.e. compressive) than for samples with no machining. In samples $1 \div 3$ made of AW-7075 alloy (fig. 15) the values of post-machining stresses are lower than residual stresses for the surface with no machining. Samples 1 and 


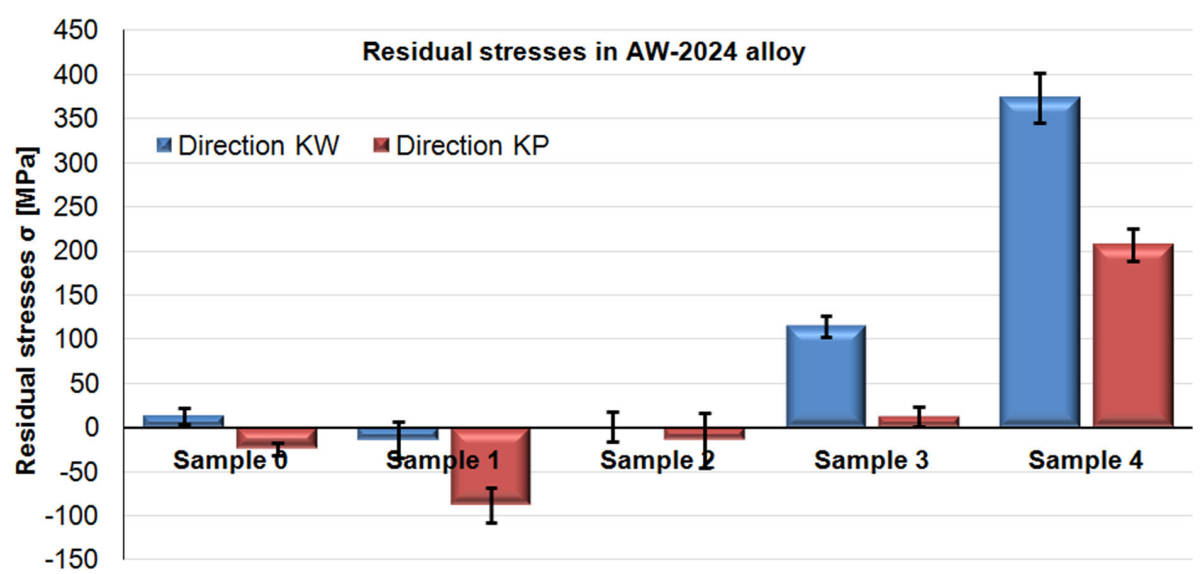

Fig. 14. Residual stresses in samples made of AW-2024 alloy and machined under various conditions (machining parameters in Table 3)



Fig. 15. Residual stresses in samples made of AW-7075 alloy and machined under various conditions (machining parameters in Table 3)

2 were machines at two selected cutting speeds $\left(\mathrm{v}_{\mathrm{c}}=400 \mathrm{~m} / \mathrm{min}\right.$ and $\left.\mathrm{v}_{\mathrm{c}}=900 \mathrm{~m} / \mathrm{min}\right)$ and with smaller cross-sections of removed layer (ae $=4$ $\mathrm{mm})$, whereas sample 3 was machined with larger cross-section of removed layer $(\mathrm{ae}=8 \mathrm{~mm})$ and at the cutting speed of $\mathrm{v}_{\mathrm{c}}=400 \mathrm{~m} / \mathrm{min}$, i.e. lower of the two selected speeds.

We may assume that in the case of AW-7075 alloy, the values of residual stresses in samples 1 $\div 3$ in two directions, i.e. KW and KP, are negative (compressive) or close to zero; unlike AW-2024 alloy, however, the stresses in rolling Direction KW are smaller than in the Direction KP which is perpendicular to $\mathrm{KW}$. In the case of sample 4 a considerable increase in residual stresses is visible, the stresses being higher in Direction KW than in Direction KP, similarly as in the case of AW-2024 alloy.

\section{SUMMARY AND CONCLUSIONS}

Measurements, monitoring, and analysis of results allow for drawing the conclusions mentioned below:

1. The structure of the samples made of AW-2024 and AW-7075 alloys is typical of rolled materials. At the surface of the sample the grains feature extended cross-sections in the rolling direction and their sizes are considerably larger within the area of the cores of the samples. The diversity of rolled plate material structures is a likely source of residual stresses.

2. Specifically large grains can be found in the area of cores of the samples made of AW-2024 alloy. In certain cases, large grain size prevented the measurement of residual stresses by means of X-ray method due to unavailability of 
sufficient number of net planes which take part in the diffraction.

3. If the cross-sections of machined layer are the same, the increase in the cutting speed will add to the values of residual stresses. Compressive stresses yield to tensile stresses, which may provide evidence of the predominance of thermal model over mechanical model (fig. 5) at high cutting speeds corresponding to HSM.

4. Consequently, we may state that increase in the cutting speed will produce increased residual stresses in the material in the direction of positive tensile stresses which are not favourable due to potential damage to the top layer.

5. In terms of machining precision and potential deformation of large-size structural elements which should be further assembled, the incidence of residual stresses should be considered as an undesirable phenomenon, irrespective of the nature (tensile; compressive) and the source (history of half-finished product manufacturing process; post-machining stresses) of the stresses.

6. Considering the above, machining parameters which are the most favourable due to the minimization of residual stresses have been applied in the case of alloys mentioned below, on the basis of diffractometric tests:

- AW-2024, sample 2: small cross-section of machined layer and high cutting speed, meaning the parameters which correspond to HSM;

- AW-7075, sample 3: relatively large crosssection of machined layer and small cutting speed, meaning the parameters which correspond to conventional machining.

\section{Acknowledgement:}

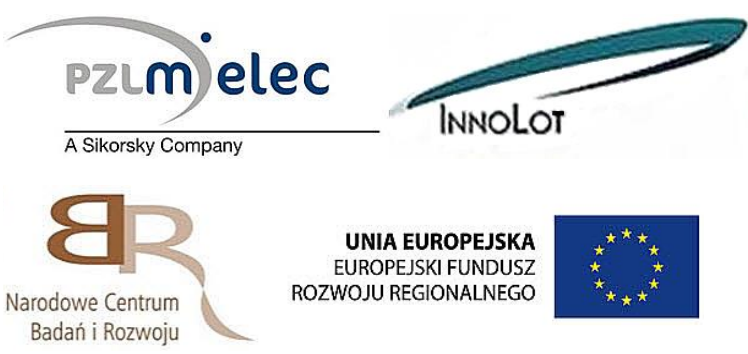

Study conducted as a part of sector-specific project INNOLOT (acronym: BloStEr) concerning the "Development of Innovative Mechanical Joints to Replace Conventional Joints in Air-
Grade Structures", co-ordinated by PZL Mielec Sp. z o.o., co-financed by the grants from Narodowe Centrum Badań i Rozwoju [National Centre for R\&D] as well as by the European Union from the European Regional Development Fund under the Innovative Economy Operational Programme.

Priority I., Measure 1.5 PO IG., Agreement No. INNOLOT/I/5/NCBR/2013

\section{REFERENCES}

1. Arasimowicz A., Piekarski R.: Pomiar naprężeń własnych metodą usuwania warstw w technologicznych warstwach wierzchnich, Postępy Nauki i Techniki, 6/2011, Pages 5-13.

2. El-Axir M.H.: A method of modeling residual stress distribution in turning for different materials, International Journal of Machine Tools and Manufacture, Volume 42, Issue 9, July 2002, Pages 1055-1063.

3. Olszak W.: Obróbka skrawaniem, WNT-Wydawnictwa Naukowo-Techniczne, Warszawa 2008.

4. Opracowania własne, prace niepublikowane, materiały informacyjne i inne.

5. Polskie Normy: PN-87/M-04250. Warstwa wierzchnia - Terminologia, 1987.

6. Polskie Normy: PN-EN 573-3:2010. Aluminium i stopy aluminium - Skład chemiczny i rodzaje wyrobów przerobionych plastycznie - Część 3: Skład chemiczny, 2005.

7. Pradeep P.: Defect Identification in GRID-LOCK $®$ Joints. A dissertation to the Graduate Faculty of North Carolina State University. 2006.

8. Stuart B.: New Airframe Construction Techniques Lowers Both Manufacturing and In-Service Costs. Metal Miner, March 29, 2010.

9. Tang Z.T., Liu Z.Q., Pan Y.Z., Wan Y., Ai X.: The influence of tool flank wear on residual stresses induced by milling aluminum alloy, Journal of Materials Processing Technology, Volume 209, Issue 9, 1 May 2009, Pages 4502-4508.

10. Waisman I. L., Phillips A.: Simplified Measurement of Residual Stresses, Proc. of the Society Experimental Stress Analisis, t. XI, 2/1952, Page102.

11. Wei-En Fu, Paul H. Cohen, Clayton O. Ruud: Experimental investigation of the machining induced residual stress tensor under mechanical loading, Journal of Manufacturing Processes, Volume 11, Issue 2, July 2009, Pages 88-96. 